\title{
Longterm follow-up in European respiratory health studies - patterns and implications
}

\author{
Ane Johannessen ${ }^{1 *}$, Giuseppe Verlato ${ }^{2 \dagger}$, Bryndis Benediktsdottir $^{3 \dagger}$, Bertil Forsberg ${ }^{4 \dagger}$, Karl Franklin $^{5 \dagger}$, \\ Thorarinn Gislason ${ }^{3+}$, Mathias Holm ${ }^{6 \dagger}$, Christer Janson ${ }^{7 \dagger}$, Rain Jögi ${ }^{8 \dagger}$, Eva Lindberg ${ }^{7 \dagger}$, Ferenc Macsali ${ }^{9 \dagger}$, \\ Ernst Omenaas ${ }^{1 \dagger}$, Francisco Gomez Real ${ }^{10 \dagger}$, Eirunn Waatevik Saure ${ }^{10 \dagger}$, Vivi Schlünssen ${ }^{11,12 \dagger}$, Torben Sigsgaard ${ }^{11 \dagger}$, \\ Trude Duelien Skorge ${ }^{13 \dagger}$, Cecilie Svanes ${ }^{13 \dagger}$, Kjell Torén ${ }^{14 \dagger}$, Marie Waatevik ${ }^{1 \dagger}$, Roy Miodini Nilsen ${ }^{1 \dagger}$ \\ and Roberto de $\mathrm{MarCo}^{2+}$
}

\begin{abstract}
Background: Selection bias is a systematic error in epidemiologic studies that may seriously distort true measures of associations between exposure and disease. Observational studies are highly susceptible to selection bias, and researchers should therefore always examine to what extent selection bias may be present in their material and what characterizes the bias in their material. In the present study we examined long-term participation and consequences of loss to follow-up in the studies Respiratory Health in Northern Europe (RHINE), Italian centers of European Community Respiratory Health Survey (I-ECRHS), and the Italian Study on Asthma in Young Adults (ISAYA).

Methods: Logistic regression identified predictors for follow-up participation. Baseline prevalence of 9 respiratory symptoms (asthma attack, asthma medication, combined variable with asthma attack and/or asthma medication, wheeze, rhinitis, wheeze with dyspnea, wheeze without cold, waking with chest tightness, waking with dyspnea) and 9 exposure-outcome associations (predictors sex, age and smoking; outcomes wheeze, asthma and rhinitis) were compared between all baseline participants and long-term participants. Bias was measured as ratios of relative frequencies and ratios of odds ratios (ROR).
\end{abstract}

Results: Follow-up response rates after 10 years were 75\% in RHINE, 64\% in I-ECRHS and 53\% in ISAYA. After 20 years of follow-up, response was 53\% in RHINE and $49 \%$ in I-ECRHS. Female sex predicted long-term participation (in RHINE OR (95\% CI) 1.30(1.22, 1.38); in I-ECRHS 1.29 (1.11, 1.50); and in ISAYA $1.42(1.25,1.61))$, as did increasing age. Baseline prevalence of respiratory symptoms were lower among long-term participants (relative deviations compared to total baseline population 0-15\% (RHINE), 0-48\% (I-ECRHS), 3-20\% (ISAYA)), except rhinitis which had a slightly higher prevalence. Most exposure-outcome associations did not differ between long-term participants and all baseline participants, except lower OR for rhinitis among ISAYA long-term participating smokers (relative deviation 17\% (smokers) and 44\% (10-20 pack years)).

Conclusions: We found comparable patterns of long-term participation and loss to follow-up in RHINE, I-ECRHS and ISAYA. Baseline prevalence estimates for long-term participants were slightly lower than for the total baseline population, while exposure-outcome associations were mainly unchanged by loss to follow-up.

\footnotetext{
* Correspondence: ane.johannessen@helse-bergen.no

${ }^{\dagger}$ Equal contributors

'Centre for Clinical Research, Haukeland University Hospital, Bergen 5021,

Norway

Full list of author information is available at the end of the article
}

\section{Ciomed Central}

C 2014 Johannessen et al.; licensee BioMed Central Ltd. This is an Open Access article distributed under the terms of the Creative Commons Attribution License (http://creativecommons.org/licenses/by/2.0), which permits unrestricted use, distribution, and reproduction in any medium, provided the original work is properly credited. The Creative Commons Public Domain Dedication waiver (http://creativecommons.org/publicdomain/zero/1.0/) applies to the data made available in this article, unless otherwise stated. 


\section{Background}

Large prospective population-based studies provide important evidence for public health interventions aiming at early disease prevention and treatment [1,2]. However, in order to draw valid scientific conclusions, data must be collected in a way that minimizes systematic errors [3]. Failing to avoid such errors in data collection could compromise the internal validity of exposure-outcome associations, leading to biased effect estimates and erroneous conclusions $[1,4,5]$.

In a population-based follow-up study data is collected repeatedly within the same cohort of study participants. Inevitably, this study design is vulnerable to loss to followup. If loss to follow-up is greater in some exposure groups than others, it can affect prevalence estimates and in some cases also exposure-outcome association estimates [6-9]. Thus, an evaluation of non-response and loss to follow-up is essential in order to determine the validity and scientific potential of population-based epidemiological studies.

In 1989, the largest European longitudinal study within the field of respiratory health was launched; the European Community Respiratory Health Survey (ECRHS) [10]. In relation to this study, Northern European countries initiated a study with postal questionnaires expanding the baseline ECRHS population to include representative populations in Iceland, Denmark, Sweden, Norway and Estonia: the Respiratory Health in Northern Europe (RHINE) study [11]. Also in Southern Europe study centers were involved in both the ECRHS as well as formed separate studies in relation with ECRHS. Italian Study on Asthma in Young Adults (ISAYA) is one such study [12].

The aim of the present paper was to examine longterm participation and consequences of loss to follow-up in Northern European and Italian study centers. We aimed to identify predictors for long-term participation, and to quantify bias in selected respiratory outcomes and exposure-outcome associations.

\section{Methods}

\section{Study population}

The overall aims of RHINE, I-ECRHS and ISAYA are to identify incidence, prevalence and risk factors for respiratory diseases such as asthma and chronic obstructive pulmonary disease, and symptoms related to such diseases. RHINE is a large Northern European prospective cohort study initiated in 1989-1992, with follow-ups in 19992000 and in 2010-2012 (Figure 1). Participating centers in RHINE are Reykjavik (Iceland), Bergen (Norway), Umeå, Uppsala and Gothenburg (Sweden), Aarhus (Denmark) and Tartu (Estonia) [11,13].

The Italian centers included in the ECRHS are Verona, Pavia and Turin. They were all included in the ECRHS in 1991-93 with a follow-up examination in 1998-2000 [14].

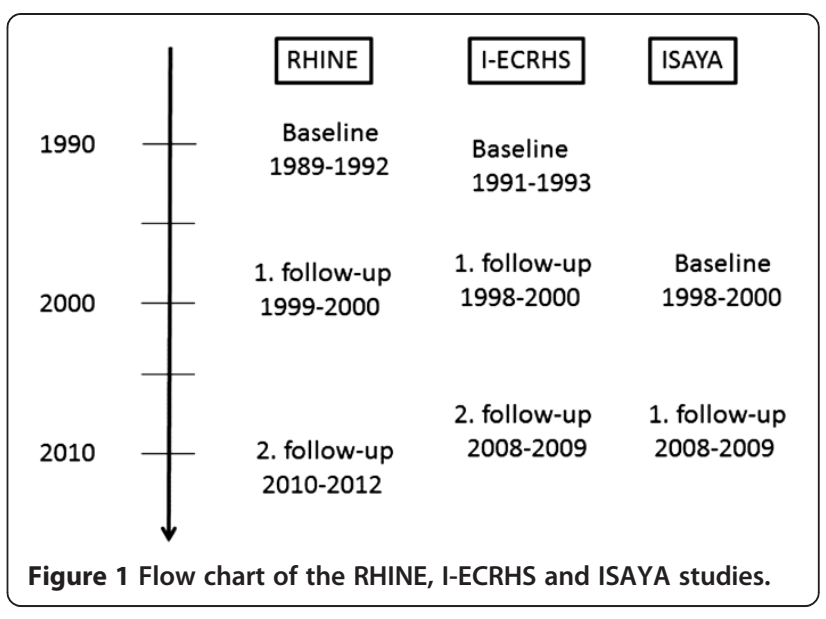

Verona also completed a second follow-up in 2008-2009 (Figure 1).

ISAYA was initially conducted in 1998-2000 and comprised nine study centers [12]. Of these, two centers, Verona and Sassari, participated in a follow-up study in 2008-2009 (Figure 1).

We examined data from the total baseline populations in each of the three studies, and compared them with baseline data for 10-yrs follow-up populations (subjects who participated both at baseline and first follow-up in the studies) and with baseline data for 20-yrs follow-up populations (subjects who participated both at baseline and both follow-up examinations in RHINE and I-ECRHS). We also examined data on associations of smoking with selected outcomes for all three studies in 1998-2000 (first follow-up study for RHINE and I-ECRHS, and baseline for ISAYA) and compared them with the same data for 10-yrs follow-up populations. The selection of 1998-2000 data for these exposure-outcome analyses was due to missing smoking information at baseline for RHINE and I-ECRHS.

In all studies, informed consent was obtained from each participant prior to each stage, and the studies were approved by regional committees of medical research ethics according to national legislations. For exact names on the regional ethics committees in each study centre, please see information in the online supplement.

\section{Selected outcomes and exposures}

The data used for the present study was collected through questionnaires with the same questions in all three studies. In RHINE, the data was collected through self-administered questionnaires, while in the Italian studies the data was collected partly through self-administered questionnaires (66\% in I-ECRHS and $72 \%$ in ISAYA) and partly by telephone interviews $(44 \%$ in I-ECRHS and $28 \%$ in ISAYA) $[14,15]$. Main outcomes for the present study were wheeze, asthma and rhinitis (see online supplement for exact question wording). In 
the online supplement, we also present baseline prevalence of other respiratory symptoms: wheeze with dyspnea, wheeze without cold, waking with chest tightness, waking with dyspnea, asthma attack last 12 months, and current asthma medication.

Selected exposure variables were sex and age at baseline, as well as study center. In addition, we inspected associations of wheeze, asthma, rhinitis with smoking exposure. Smoking variables were self-reported never/ ex/current smoker, and smokers defined as $<10$ pack years, $10-20$ pack years and $\geq 20$ pack years, with one pack year being defined as having smoked 20 cigarettes a day for one year.

\section{Statistical methods}

All analyses were performed using Stata/SE version 12.1 (StataCorp, Texas, USA) software for Windows. Logistic regression analyses were performed to estimate associations of age, sex and study center with long-term participation, using a binary indicator of participation in follow-up $(0=$ no, $1=$ yes $)$ as dependent variable.

When examining if prevalence and association estimates differed between all baseline and long-term participants, we followed methods used by among others Nilsen et al., using baseline data as the reference $[8,16-19]$. The methodology used by Nilsen et al. is described in detail in the remainder of this section, applying it to the focus of interest in the present study. We estimated baseline prevalence (with 95\% confidence intervals) of all respiratory outcomes for all baseline participants, for those who participated at baseline and first follow-up (10-yrs follow-up), and for those who participated at baseline and both follow-ups (20-yrs follow-up). We assessed ratios of baseline prevalence of long-term participants over all baseline participants, in order to examine potential bias in prevalence between these various populations. The 9 selected exposure-outcome associations were investigated through logistic regression analyses, and ratios of baseline ORs among the various forms of long-term participants over all baseline participants were calculated $[8,16,18]$. In both ratios of prevalence estimates and ratios of ORs, a ratio below 1 indicates under-estimation in the subsample compared to the total baseline population (long-term participants have a lower prevalence or weaker exposureoutcome association than all baseline participants), while a ratio above 1 indicates an over-estimation (long-term participants have a higher prevalence or stronger exposure-outcome association). For ratios of ORs, this interpretation is reversed if the exposure has a protective effect on the outcome.

For both ratios of prevalence estimates and ratios of ORs, we computed $95 \%$ confidence intervals to assess the uncertainty of the ratio through bootstrapping [20]. For each of the studies, we identified long-term participants (n) and the remainder of the baseline population (m) in the total baseline population data file $(m+n)$. We performed 2000 random re-samplings from the total baseline population, and created 2000 alternative data sets with size $\mathrm{m}+\mathrm{n}$. For each sample, we computed the ratios of long-term participants (n) over all baseline participants $(m+n)$. By extracting the 2.5 percentile and the 97.5 percentile from these 2000 ratio estimates, we retrieved the $95 \%$ confidence interval.

\section{Results}

\section{Response rates}

In RHINE, the baseline study in 1989-1992 comprised 21659 subjects aged 20-44 yrs (Table 1). In the first follow-up in 1999-2000, 75\% answered a new questionnaire. In the second follow-up in 2010-12, response rate among those who had participated in the previous two stages was $53 \%$.

In I-ECRHS centers, the baseline study in 1991-93 comprised 6029 subjects aged $20-45$ yrs. In the first follow-up in 1998-2000, response rate was 64\%, and

\begin{tabular}{|c|c|c|c|}
\hline Study center & Baseline & 10-yrs follow-up & 20-yrs follow-up \\
\hline \multicolumn{4}{|l|}{$\overline{\mathrm{RHINE}}$} \\
\hline Aarhus & 3614 (85\%) & 2589 (72\%) & 1959 (54\%) \\
\hline Bergen & 3449 (82\%) & 2506 (73\%) & 1833 (53\%) \\
\hline Gothenburg & 2861 (83\%) & 2175 (76\%) & 1496 (52\%) \\
\hline Reykjavik & 2899 (84\%) & 1967 (68\%) & 1572 (54\%) \\
\hline Tartu & 2449 (85\%) & 1705 (70\%) & 1066 (44\%) \\
\hline Umea & 3273 (92\%) & $2621(80 \%)$ & 1745 (53\%) \\
\hline Uppsala & 3114 (89\%) & 2543 (82\%) & 1770 (57\%) \\
\hline TOTAL & 21659 (86\%) & 16106 (75\%) & 11441 (53\%) \\
\hline \multicolumn{4}{|l|}{ Italian ECRHS } \\
\hline Verona & 2711 (92\%) & 1737 (64\%) & 1338 (49\%) \\
\hline Pavia & $816(86 \%)$ & 701 (86\%) & - \\
\hline Turin & 2502 (84\%) & 1443 (58\%) & - \\
\hline TOTAL & $6029(88 \%)$ & 3881 (64\%) & $1338(49 \%)^{b}$ \\
\hline \multicolumn{4}{|l|}{ ISAYA } \\
\hline Verona & 2158 (74\%) & $1421(66 \%)$ & - \\
\hline Sassari & $2053(70 \%)$ & 810 (39\%) & - \\
\hline TOTAL & 4211 (72\%) & 2231 (53\%) & - \\
\hline
\end{tabular}

${ }^{a}$ Subjects who have answered one or more of the following questions at each of the relevant study stages: asthma, hay fever, wheeze. Baseline: 1989-92 in RHINE, 1991-93 in Italian ECRHS, 1998-2000 in ISAYA. 10-yrs follow-up: 1999-2000 in RHINE, 1998-2000 in Italian ECRHS, 2008-09 in ISAYA. 20-yrs follow-up: 2010-12 in RHINE, 2008-09 in Italian ECRHS.

Response rates are calculated based on those invited to baseline for baseline populations, and based on those participating in baseline for follow-up populations.

${ }^{\mathrm{b}}$ Response rate for 20-yrs follow-up in Italian ECRHS is calculated based on original response rate in Verona. 
from the Verona study center $49 \%$ participated also in the second follow-up in 2008-09.

In ISAYA, 4211 subjects aged 20-45 yrs participated at baseline in 1998-2000. At follow-up 10 yrs later, 53\% participated. The initial response rates at baseline were high across all centres, varying from $70 \%$ in Sassari (Italy) to $92 \%$ in Umeå (Sweden) and Verona (Italy) (Table 1, [12,21]). Ten years later, response rates varied from $39 \%$ in Sassari (Italy) to $86 \%$ in Pavia (Italy). When looking at participants 20 years after baseline, response rates varied from $44 \%$ in Tartu (Estonia) to $57 \%$ in Uppsala (Sweden).

\section{Determinants of participation}

Table 2 presents associations of age, sex and study center, with 10-yrs and 20-yrs follow-up participation, respectively. OR for long-term participation increased with increasing age, especially in RHINE and I-ECRHS. Women were more often long-term participants than men in all three studies. The propensity to participate varied significantly across centers: the OR for long-term participation in RHINE was especially high in Umea and Uppsala for 10-yrs follow-up, and in Aarhus and Uppsala for 20-yrs follow-up. In I-ECRHS and in ISAYA, Pavia and Verona had the highest ORs for long-term participation, respectively.

\section{Baseline prevalence of respiratory symptoms}

Prevalence estimates of wheeze, asthma and rhinitis at baseline are shown in Table 3 and in Additional file 1: e-Table S1 in the online supplement for each study center separately. Baseline prevalence of several other respiratory symptoms is presented in the online supplement (Additional file 1: e-Table S2). In RHINE, prevalence of baseline wheeze last 12 months, wheeze with dyspnea, wheeze without cold, waking with chest tightness and waking with dyspnea were significantly lower in the long-term participants compared to the total baseline population, while the prevalence of rhinitis was higher. Waking with dyspnea had a relative deviation of $15 \%$ between the 20-yrs follow-up participants and the total baseline population, while all other symptoms differed by $<10 \%$ between the long-term population and the total baseline population.

In I-ECRHS, the 10-yrs follow-up population and the total baseline population did not differ in baseline prevalence of any of the respiratory outcomes. Regarding 20-yrs follow-up, however, baseline prevalence of rhinitis was higher compared to the corresponding estimate in the total baseline population (relative deviation 14\%), while wheeze with dyspnea and waking with dyspnea was lower (relative deviations $48 \%$ and 23\%, respectively). In ISAYA, baseline prevalence of wheeze last 12 months, wheeze with dyspnea and waking with chest
Table 2 Predictors for long-term participation in RHINE, Italian ECRHS and ISAYA, odds ratios with $95 \%$ confidence intervals

\begin{tabular}{|c|c|c|c|}
\hline Study centre & & 10-yrs follow-up & 20-yrs follow-up \\
\hline \multirow[t]{14}{*}{ RHINE } & $20-25$ yrs & Ref & Ref \\
\hline & $25-30$ yrs & $1.18(1.08,1.29)$ & $1.15(1.06,1.24)$ \\
\hline & $30-35$ yrs & $1.30(1.19,1.42)$ & $1.31(1.20,1.42)$ \\
\hline & $35-40$ yrs & $1.33(1.21,1.46)$ & $1.40(1.29,1.52)$ \\
\hline & $40-44$ yrs & $1.55(1.40,1.72)$ & $1.59(1.45,1.73)$ \\
\hline & Men & Ref & Ref \\
\hline & Women & $1.30(1.22,1.38)$ & $1.28(1.21,1.35)$ \\
\hline & Aarhus & $1.22(1.10,1.36)$ & $1.50(1.35,1.66)$ \\
\hline & Bergen & $1.29(1.16,1.44)$ & $1.44(1.30,1.60)$ \\
\hline & Gothenburg & $1.52(1.35,1.70)$ & $1.37(1.22,1.52)$ \\
\hline & Reykjavik & Ref & $1.47(1.31,1.64)$ \\
\hline & Tartu & $1.14(1.01,1.28)$ & Ref \\
\hline & Umea & $1.93(1.72,2.17)$ & $1.42(1.28,1.58)$ \\
\hline & Uppsala & $2.14(1.90,2.41)$ & $1.65(1.48,1.83)$ \\
\hline Italian & $20-25$ yrs & Ref & Ref \\
\hline \multirow[t]{9}{*}{ ECRHS } & $25-30 \mathrm{yrs}$ & $0.91(0.77,1.07)$ & $0.96(0.76,1.22)$ \\
\hline & $30-35$ yrs & $1.07(0.90,1.27)$ & $1.27(1.00,1.63)$ \\
\hline & $35-40$ yrs & $1.29(1.08,1.54)$ & $1.50(1.17,1.92)$ \\
\hline & $40-44$ yrs & $1.50(1.26,1.80)$ & $1.63(1.26,2.09)$ \\
\hline & Men & Ref & Ref \\
\hline & Women & $1.18(1.06,1.31)$ & $1.29(1.11,1.50)$ \\
\hline & Verona & $1.33(1.19,1.49)$ & - \\
\hline & Pavia & $4.48(3.62,5.55)$ & - \\
\hline & Turin & Ref & - \\
\hline \multirow[t]{9}{*}{ ISAYA } & $20-25$ yrs & Ref & - \\
\hline & $25-30 \mathrm{yrs}$ & $1.08(0.89,1.32)$ & - \\
\hline & $30-35$ yrs & $1.19(0.97,1.45)$ & - \\
\hline & $35-40$ yrs & $1.29(1.05,1.60)$ & - \\
\hline & $40-44$ yrs & $1.19(0.96,1.47)$ & - \\
\hline & Men & Ref & - \\
\hline & Women & $1.42(1.25,1.61)$ & - \\
\hline & Verona & $2.93(2.59,3.33)$ & - \\
\hline & Sassari & Ref & - \\
\hline
\end{tabular}

tightness was lower in the 10-yrs follow-up population compared to the total baseline population (relative deviations $9 \%, 20 \%$ and $11 \%$, respectively).

A closer look at the study centers (Additional file 1: e-Table S1) shows more heterogeneous study centers in RHINE than in I-ECRHS and ISAYA. In Reykjavik, baseline asthma and rhinitis was higher in long-term participants compared to total baseline population, the same was true for rhinitis in Tartu and Umea. Aarhus, Bergen, Gothenburg and Tartu had lower baseline prevalence of 
Table 3 Prevalence (with $95 \%$ confidence intervals) of respiratory symptoms at baseline in total baseline population, population at 10-yrs follow-up and population at 20-yrs follow-up, and differences between these groups given as ratios of baseline symptom prevalence (with bootstrapped $95 \%$ confidence intervals) in population at 10-yrs follow-up over total baseline population, and in population at 20-yrs follow-up over total baseline population ${ }^{\text {a }}$

\begin{tabular}{|c|c|c|c|c|c|c|}
\hline & & $\begin{array}{l}\text { Baseline population } \\
(95 \% \mathrm{Cl})\end{array}$ & $\begin{array}{l}\text { 10-yrs follow-up } \\
\text { population }(95 \% \mathrm{Cl})\end{array}$ & $\begin{array}{l}\text { Ratio of prevalences } \\
(95 \% \mathrm{Cl})^{b}\end{array}$ & $\begin{array}{l}20 \text {-yrs follow-up } \\
\text { population }(95 \% \mathrm{Cl})\end{array}$ & $\begin{array}{l}\text { Ratio of prevalences } \\
(95 \% C l)^{b}\end{array}$ \\
\hline \multirow[t]{3}{*}{ Wheeze } & RHINE & $22.2 \%(20.4,21.6)$ & $21.5 \%(19.9,21.3)$ & $0.97(0.95,0.99)$ & $20.5 \%(19.0,20.6)$ & $0.92(0.90,0.95)$ \\
\hline & Italian ECRHS & $10.0 \%(9.0,10.5)$ & $10.2 \%(8.9,10.8)$ & $1.02(0.96,1.07)$ & $10.1 \%(8.0,11.2)$ & $1.01(0.87,1.14)$ \\
\hline & ISAYA & $15.1 \%(12.4,14.6)$ & $13.7 \%(11.1,13.8)$ & $0.91(0.84,0.98)$ & - & - \\
\hline \multirow[t]{3}{*}{ Asthma } & RHINE & $4.7 \%(4.3,5.0)$ & $4.8 \%(4.4,5.2)$ & $1.02(0.99,1.05)$ & $4.6 \%(4.3,5.1)$ & $0.98(0.92,1.03)$ \\
\hline & Italian ECRHS & $4.2 \%(3.6,4.6)$ & $4.2 \%(3.5,4.7)$ & $1.00(0.91,1.09)$ & $3.8 \%(2.5,4.5)$ & $0.90(0.67,1.10)$ \\
\hline & ISAYA & $5.3 \%(4.4,5.8)$ & $5.0 \%(3.8,5.6)$ & $0.94(0.83,1.07)$ & - & - \\
\hline \multirow[t]{3}{*}{ Rhinitis } & RHINE & $19.3 \%(19.3,20.5)$ & $19.8 \%(19.7,21.1)$ & $1.03(1.01,1.04)$ & $19.9 \%(19.9,21.5)$ & $1.03(1.00,1.06)$ \\
\hline & Italian ECRHS & $15.9 \%(14.8,16.6)$ & $15.8 \%(14.4,16.7)$ & $0.99(0.95,1.03)$ & $18.2 \%(15.8,20.0)$ & $1.14(1.02,1.26)$ \\
\hline & ISAYA & $20.7 \%(19.3,21.8)$ & $21.1 \%(19.3,22.7)$ & $1.02(0.96,1.08)$ & - & - \\
\hline
\end{tabular}

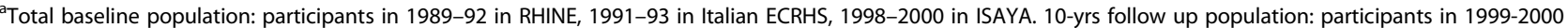
in RHINE and 1998-2000 in Italian ECRHS, 2008-09 in ISAYA. 20-yrs follow-up population: participants in 2010-12 in RHINE, 2008-09 in Italian ECRHS.

${ }^{b}$ Corrected for inter-dependency between long-term participants and total baseline participants, by using a non-parametric bootstrap method. Significant differences between long-term participants and all baseline participants are marked in bold font.

wheeze among long-term participants than among all baseline participants, for Aarhus this was also the case with asthma.

\section{Associations of age and sex with respiratory outcomes}

Table 4 shows ORs for age (5-year-intervals) and female sex with regard to baseline wheeze, asthma and rhinitis in RHINE, I-ECRHS and ISAYA, and ratios of ORs between long-term and total baseline participants. There were no significant differences between the ORs of long-term participants and the ORs of all baseline participants in any of the three studies. When stratified by study centers, associations for long-term participants and total baseline participations were more diverse, especially for Pavia, Aarhus and Reykjavik (Additional file 1: e-Table S3 and e-Table S4).

\section{Associations of smoking with respiratory outcomes} In the studies performed in 1998-2000, information on smoking habits was included in RHINE, I-ECRHS and ISAYA. Tables 5, 6 and 7 show ORs for associations of smoking exposure with wheeze, asthma and rhinitis, respectively, as well as the ratios of ORs between 10-yrs follow-up participants and total baseline participants.

There was increased OR for wheeze with smoking in all three studies. The ORs differed slightly between 10-yrs follow-up participants and total baseline participants, but all relative differences were below $15 \%$ and not statistically significant (Table 5). There were no significant associations between smoking and asthma in the three studies, with the exception of an association between ex-smokers and asthma in I-ECRHS (Table 6). None of the ORs between long-term participants and total baseline population differed significantly from each other.
Current smoking and smoking more than 10 pack years were both associated with a lower OR for rhinitis in all study centers (Table 7). In RHINE and I-ECRHS there were no differences in ORs between long-term and all baseline participants, while the OR of current smokers and subjects with 10-20 pack years were significantly lower for long-term than all baseline participants in ISAYA (17\% and $44 \%$ relative difference, respectively).

\section{Discussion}

The present study of long-term participation in RHINE, I-ECRHS and ISAYA showed that increasing age and female sex were predictors for long-term participations. When comparing long-term participants to all baseline participants, we found lower baseline prevalence of several respiratory symptoms among long-term participants compared to all baseline participants. However, analyses of exposure-outcome associations showed only minor differences between long-term participants and all baseline participants.

\section{Characteristics and bias associated with long-term association}

That older people and women are more prone to participate in follow-up studies than younger subjects and men is in line with previous studies [22-27]. Several studies have furthermore shown that non-responders tend to be smokers to a larger degree than responders [22,25-28]. At the baseline studies in RHINE and I-ECRHS, we did not have information on smoking habits among responders and non-responders, but a previous report from ISAYA showed that smokers were over-represented among late responders compared to early responders [15]. 
Table 4 Associations between increasing age (5-year intervals) and female sex and the respiratory symptoms wheeze, asthma and rhinitis at baseline (odds ratios with $95 \%$ confidence intervals) in total baseline population, population at 10-yrs follow-up and population at 20-yrs follow-up, and differences between these groups given as ratios of odds ratios (with bootstrapped $95 \%$ confidence intervals) in population at $\mathbf{1 0}$-yrs follow-up over total baseline population, and in population at 20-yrs follow-up over total baseline population ${ }^{\text {a }}$

\begin{tabular}{|c|c|c|c|c|c|c|c|}
\hline & & & $\begin{array}{l}\text { Baseline population } \\
\text { OR }(95 \% \mathrm{Cl})\end{array}$ & $\begin{array}{l}\text { 10-yrs follow-up } \\
\text { population OR }(95 \% \mathrm{Cl})\end{array}$ & $\begin{array}{l}\text { Ratio of ORs } \\
(95 \% C l)^{b}\end{array}$ & $\begin{array}{l}\text { 20-yrs follow-up } \\
\text { population OR }(95 \% \mathrm{Cl})\end{array}$ & $\begin{array}{l}\text { Ratio of ORs } \\
(95 \% C l)^{b}\end{array}$ \\
\hline \multirow[t]{6}{*}{ Wheeze } & Age & RHINE & $1.00(0.98,1.02)$ & $1.01(0.98,1.03)$ & $1.01(0.99,1.02)$ & $0.98(0.95,1.02)$ & $0.98(0.96,1.01)$ \\
\hline & & Italian ECRHS & $1.10(1.03,1.17)$ & $1.10(1.02,1.19)$ & $1.00(0.96,1.05)$ & $1.15(1.01,1.31)$ & $1.05(0.93,1.18)$ \\
\hline & & ISAYA & $0.97(0.91,1.03)$ & $0.96(0.88,1.05)$ & $0.99(0.94,1.07)$ & - & - \\
\hline & Sex & RHINE & $0.95(0.90,1.02)$ & $0.99(0.92,1.07)$ & $1.04(1.00,1.08)$ & $0.96(0.87,1.05)$ & $1.01(0.94,1.07)$ \\
\hline & & Italian ECRHS & $0.76(0.64,0.90)$ & $0.74(0.60,0.91)$ & $0.97(0.86,1.10)$ & $0.63(0.44,0.91)$ & $0.83(0.60,1.15)$ \\
\hline & & ISAYA & $0.81(0.69,0.96)$ & $0.79(0.62,1.01)$ & $0.98(0.82,1.16)$ & - & - \\
\hline \multirow[t]{6}{*}{ Asthma } & Age & RHINE & $0.98(0.93,1.02)$ & $0.98(0.93,1.03)$ & $1.00(0.97,1.03)$ & $0.96(0.90,1.02)$ & $0.98(0.94,1.03)$ \\
\hline & & Italian ECRHS & $0.99(0.90,1.08)$ & $0.94(0.84,1.05)$ & $0.95(0.89,1.01)$ & $0.88(0.71,1.08)$ & $0.89(0.73,1.06)$ \\
\hline & & ISAYA & $0.92(0.83,1.02)$ & $0.95(0.83,1.09)$ & $1.03(0.93,1.15)$ & - & - \\
\hline & Sex & RHINE & $1.16(1.02,1.32)$ & $1.21(1.05,1.40)$ & $1.04(0.97,1.13)$ & $1.13(0.95,1.35)$ & $0.97(0.87,1.11)$ \\
\hline & & Italian ECRHS & $0.84(0.66,1.08)$ & $0.82(0.60,1.12)$ & $0.98(0.80,1.18)$ & $0.60(0.34,1.06)$ & $0.71(0.41,1.18)$ \\
\hline & & ISAYA & $1.08(0.82,1.41)$ & $0.94(0.64,1.38)$ & $0.87(0.67,1.16)$ & - & - \\
\hline \multirow[t]{6}{*}{ Rhinitis } & Age & RHINE & $0.97(0.95,0.99)$ & $0.97(0.95,1.00)$ & $1.00(0.99,1.02)$ & $0.97(0.94,1.00)$ & $1.00(0.98,1.02)$ \\
\hline & & Italian ECRHS & $0.94(0.89,0.99)$ & $0.93(0.88,0.99)$ & $0.99(0.96,1.03)$ & $0.91(0.83,1.01)$ & $0.97(0.89,1.07)$ \\
\hline & & ISAYA & $0.93(0.88,0.98)$ & $0.91(0.84,0.98)$ & $0.98(0.93,1.03)$ & - & - \\
\hline & Sex & RHINE & $0.99(0.92,1.05)$ & $1.01(0.93,1.09)$ & $1.02(0.98,1.06)$ & $1.01(0.92,1.11)$ & $1.02(0.96,1.09)$ \\
\hline & & Italian ECRHS & $0.93(0.81,1.07)$ & $0.89(0.75,1.06)$ & $0.96(0.86,1.06)$ & $0.73(0.55,0.97)$ & $0.78(0.61,1.01)$ \\
\hline & & ISAYA & $0.85(0.74,0.99)$ & $0.79(0.64,0.97)$ & $0.93(0.81,1.06)$ & - & - \\
\hline
\end{tabular}

${ }^{a}$ Total baseline population: participants in 1989-92 in RHINE, 1991-93 in Italian ECRHS, 1998-2000 in ISAYA. 10-yrs follow up population: participants in 1999-2000 in RHINE and 1998-2000 in Italian ECRHS, 2008-09 in ISAYA. 20-yrs follow-up population: participants in 2010-12 in RHINE, 2008-09 in Italian ECRHS. ${ }^{\circ}$ Corrected for inter-dependency between long-term participants and total baseline participants, by using a non-parametric bootstrap method. Significant associations between risk factors and respiratory symptoms are marked in bold font, as well as significant differences between long-term participants and all baseline participants.

Many studies report response rates as an indicator of the data generalizability. However, it has been pointed out that even studies with high response rates may have biased effect estimates if the non-response is not random [7]. Results from the present study indicated that long-term participants had less respiratory symptoms compared to all baseline participants in RHINE, ISAYA and I-ECRHS, with the exception of rhinitis. In the literature, we find studies that are both in accordance and in discordance with our results [14,15,22,25,28-30]. These differences between studies show the importance of assessing selection bias in every longitudinal study, rather than simply stating the response rate $[26,31]$.

Interestingly, two of the reports that are in contradiction with the results from our study are from I-ECRHS and ISAYA $[14,15]$. These reports showed that there was a higher prevalence of respiratory symptoms among early responders than late responders in baseline ISAYA and I-ECRHS, and a higher symptom prevalence among those who participated in both the screening part and the clinical part of the baseline ECRHS than among those who participated only in the screening part. That the Italian papers have focused on late responders at baseline may partly explain the diverging results regarding symptom prevalence. Although responding late, they were baseline participants, and as such these subjects are included in the total baseline population of the present study. Also, even if those who participated in the screening questionnaire but refused to take part in the clinical part of the baseline ECRHS can be defined as non-responders in the clinical study, the follow-up time between these two parts of the baseline ECRHS was short and consequently not comparable to the present study.

In both RHINE and I-ECRHS we defined 20-yrs followup participation as subjects who participated at baseline and both follow-up studies. This response rate was 53\% in RHINE, but a noteworthy proportion of subjects participated at baseline and at the second follow-up, but not in the first follow-up. If considering participants who were part of the baseline and the second follow-up study, regardless of participation in the first follow-up study, the 20-yrs response rate in RHINE was raised from 53\% to 61\% (13 128 participants). Additional analyses showed 
Table 5 Associations between smoking status and pack years and wheeze at baseline (odds ratios with $95 \%$ confidence intervals) in total baseline population and population at 10-yrs follow-up, and differences between these groups given as ratios of odds ratios (with bootstrapped $95 \%$ confidence intervals) in population at 10 -yrs follow-up over total baseline population ${ }^{a}$

\begin{tabular}{|c|c|c|c|c|}
\hline & & Baseline population OR $(95 \% \mathrm{Cl})$ & 10-yrs follow-up population OR $(95 \% \mathrm{Cl})$ & Ratio of ORs $(95 \% \mathrm{Cl})^{b}$ \\
\hline \multirow[t]{3}{*}{ Ex-smokers } & RHINE & $1.26(1.13,1.40)$ & $1.26(1.11,1.44)$ & $1.00(0.93,1.08)$ \\
\hline & Italian ECRHS & $1.46(0.94,2.27)$ & $1.53(0.95,2.48)$ & $1.05(0.86,1.28)$ \\
\hline & ISAYA & $1.99(1.53,2.60)$ & $2.11(1.46,3.05)$ & $1.06(0.81,1.37)$ \\
\hline \multirow[t]{3}{*}{ Current smokers } & RHINE & $3.12(2.84,3.42)$ & $3.21(2.87,3.59)$ & $1.03(0.97,1.10)$ \\
\hline & Italian ECRHS & $3.31(2.32,4.72)$ & $3.18(2.13,4.75)$ & $0.96(0.79,1.17)$ \\
\hline & ISAYA & $3.65(2.99,4.45)$ & $3.87(2.92,5.12)$ & $1.06(0.87,1.31)$ \\
\hline \multirow[t]{3}{*}{ 1-10 pack years } & RHINE & $1.69(1.53,1.86)$ & $1.71(1.51,1.92)$ & $1.01(0.94,1.08)$ \\
\hline & Italian ECRHS & $1.58(1.03,2.41)$ & $1.67(1.05,2.67)$ & $1.06(0.87,1.30)$ \\
\hline & ISAYA & $2.50(2.03,3.08)$ & $2.71(2.02,3.64)$ & $1.08(0.88,1.33)$ \\
\hline \multirow[t]{3}{*}{ 10-20 pack years } & RHINE & $2.91(2.57,3.31)$ & $2.92(2.50,3.40)$ & $1.00(0.92,1.09)$ \\
\hline & Italian ECRHS & $2.77(1.76,4.35)$ & $2.60(1.56,4.33)$ & $0.94(0.71,1.20)$ \\
\hline & ISAYA & $3.95(3.01,5.19)$ & $3.98(2.66,5.96)$ & $1.01(0.73,1.36)$ \\
\hline \multirow[t]{3}{*}{$20+$ pack years } & RHINE & $4.37(3.75,5.10)$ & $3.99(3.30,4.82)$ & $0.91(0.82,1.02)$ \\
\hline & Italian ECRHS & $4.36(2.73,6.98)$ & $3.70(2.16,6.34)$ & $0.85(0.64,1.10)$ \\
\hline & ISAYA & $7.69(5.49,10.76)$ & $7.89(4.87,12.80)$ & $1.03(0.71,1.47)$ \\
\hline
\end{tabular}

${ }^{a}$ Total baseline population: participants in 1999-2000 in RHINE and 1998-2000 in Italian ECRHS and ISAYA. 10-yrs follow-up population: participants in 2010-12 in RHINE 2008-09 in Italian ECRHS and ISAYA. ${ }^{\mathrm{b}}$ Corrected for inter-dependency between long-term participants and total baseline participants, by using a non-parametric bootstrap method. Significant associations between risk factors and respiratory symptoms are marked in bold font, as well as significant differences between long-term participants and all baseline participants.

Table 6 Associations between smoking status and pack years and asthma at baseline (odds ratios with $95 \%$ confidence intervals) in total baseline population and population at 10-yrs follow-up, and differences between these groups given as ratios of odds ratios (with bootstrapped $95 \%$ confidence intervals) in population at 10-yrs follow-up over total baseline population $^{\mathrm{a}}$

\begin{tabular}{|c|c|c|c|c|}
\hline & & Baseline population OR $(95 \% \mathrm{Cl})$ & 10-yrs follow-up population OR $(95 \% \mathrm{Cl})$ & Ratio of ORs $(95 \% \mathrm{Cl})^{b}$ \\
\hline \multirow[t]{3}{*}{ Ex-smokers } & RHINE & $1.05(0.89,1.22)$ & $1.09(0.91,1.31)$ & $1.04(0.95,1.14)$ \\
\hline & Italian ECRHS & $1.69(1.01,2.83)$ & $1.93(1.11,3.36)$ & $1.14(0.94,1.42)$ \\
\hline & ISAYA & $1.35(0.94,1.95)$ & $1.47(0.90,2.40)$ & $1.09(0.75,1.47)$ \\
\hline \multirow[t]{3}{*}{ Current smokers } & RHINE & $1.08(0.92,1.25)$ & $1.02(0.84,1.24)$ & $0.94(0.84,1.07)$ \\
\hline & Italian ECRHS & $0.72(0.40,1.31)$ & $0.67(0.33,1.36)$ & $0.93(0.60,1.31)$ \\
\hline & ISAYA & $0.94(0.68,1.28)$ & $0.71(0.44,1.15)$ & $0.76(0.51,1.07)$ \\
\hline \multirow[t]{3}{*}{ 1-10 pack years } & RHINE & $1.04(0.89,1.21)$ & $1.11(0.93,1.34)$ & $1.07(0.97,1.18)$ \\
\hline & Italian ECRHS & $1.35(0.80,2.30)$ & $1.59(0.89,2.84)$ & $1.18(0.91,1.50)$ \\
\hline & ISAYA & $1.18(0.88,1.60)$ & $1.09(0.72,1.67)$ & $0.92(0.67,1.22)$ \\
\hline \multirow[t]{3}{*}{ 10-20 pack years } & RHINE & $1.04(0.84,1.30)$ & $1.07(0.82,1.40)$ & $1.03(0.88,1.18)$ \\
\hline & Italian ECRHS & $0.77(0.35,1.68)$ & $0.72(0.29,1.76)$ & $0.94(0.48,1.35)$ \\
\hline & ISAYA & $0.91(0.56,1.46)$ & $0.84(0.41,1.69)$ & $0.92(0.49,1.49)$ \\
\hline \multirow[t]{3}{*}{ 20+ pack years } & RHINE & $1.19(0.91,1.56)$ & $1.05(0.74,1.48)$ & $0.88(0.69,1.08)$ \\
\hline & Italian ECRHS & $0.68(0.29,1.61)$ & $0.58(0.21,1.57)$ & $0.85(0.41,1.26)$ \\
\hline & ISAYA & $0.71(0.35,1.47)$ & $0.45(0.14,1.50)$ & $0.63(0.19,1.43)$ \\
\hline
\end{tabular}

${ }^{a}$ Total baseline population: participants in 1999-2000 in RHINE and 1998-2000 in Italian ECRHS and ISAYA. 10-yrs follow-up population: participants in 2010-12 in RHINE, 2008-09 in Italian ECRHS and ISAYA. ${ }^{b}$ Corrected for inter-dependency between long-term participants and total baseline participants, by using a non-parametric bootstrap method. Significant associations between risk factors and respiratory symptoms are marked in bold font, as well as significant differences between long-term participants and all baseline participants. 
Table 7 Associations between smoking status and pack years and rhinitis at baseline (odds ratios with $95 \%$ confidence intervals) in total baseline population and population at 10-yrs follow-up, and differences between these groups given as ratios of odds ratios (with bootstrapped $95 \%$ confidence intervals) in population at 10-yrs follow-up over total baseline population $^{a}$

\begin{tabular}{|c|c|c|c|c|}
\hline & & Baseline population OR $(95 \% \mathrm{Cl})$ & 10-yrs follow-up population OR $(95 \% \mathrm{Cl})$ & Ratio of ORs $(95 \% \mathrm{Cl})^{b}$ \\
\hline \multirow[t]{3}{*}{ Ex-smokers } & RHINE & $0.92(0.83,1.01)$ & $0.92(0.83,1.03)$ & $1.00(0.95,1.06)$ \\
\hline & Italian ECRHS & $0.97(0.71,1.32)$ & $0.93(0.66,1.32)$ & $0.96(0.82,1.12)$ \\
\hline & ISAYA & $1.10(0.89,1.35)$ & $1.03(0.78,1.37)$ & $0.94(0.76,1.14)$ \\
\hline \multirow[t]{3}{*}{ Current smokers } & RHINE & $0.80(0.73,0.88)$ & $0.80(0.71,0.89)$ & $1.00(0.94,1.07)$ \\
\hline & Italian ECRHS & $0.68(0.51,0.92)$ & $0.71(0.50,1.00)$ & $1.04(0.87,1.22)$ \\
\hline & ISAYA & $0.71(0.60,0.85)$ & $0.59(0.46,0.76)$ & $0.83(0.69,0.99)$ \\
\hline \multirow[t]{3}{*}{ 1-10 pack years } & RHINE & $0.92(0.84,1.01)$ & $0.91(0.81,1.01)$ & $0.99(0.93,1.04)$ \\
\hline & Italian ECRHS & $1.00(0.75,1.35)$ & $1.06(0.76,1.47)$ & $1.06(0.90,1.23)$ \\
\hline & ISAYA & $0.99(0.84,1.17)$ & $0.96(0.76,1.20)$ & $0.97(0.83,1.12)$ \\
\hline \multirow[t]{3}{*}{ 10-20 pack years } & RHINE & $0.77(0.67,0.88)$ & $0.80(0.68,0.94)$ & $1.04(0.96,1.14)$ \\
\hline & Italian ECRHS & $0.58(0.38,0.89)$ & $0.55(0.34,0.89)$ & $0.95(0.72,1.18)$ \\
\hline & ISAYA & $0.57(0.43,0.76)$ & $0.32(0.20,0.51)$ & $0.56(0.36,0.79)$ \\
\hline \multirow[t]{3}{*}{$20+$ pack years } & RHINE & $0.67(0.56,0.80)$ & $0.69(0.56,0.86)$ & $1.03(0.91,1.16)$ \\
\hline & Italian ECRHS & $0.63(0.40,0.99)$ & $0.62(0.37,1.04)$ & $0.98(0.75,1.25)$ \\
\hline & ISAYA & $0.41(0.27,0.62)$ & $0.29(0.15,0.56)$ & $0.71(0.38,1.12)$ \\
\hline
\end{tabular}

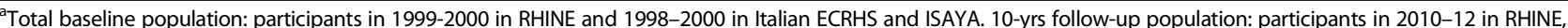
2008-09 in Italian ECRHS and ISAYA. ${ }^{\mathrm{b}}$ Corrected for inter-dependency between long-term participants and total baseline participants, by using a non-parametric bootstrap method. Significant associations between risk factors and respiratory symptoms are marked in bold font, as well as significant differences between long-term participants and all baseline participants.

that the tendencies both regarding prevalence estimates and exposure-outcome associations remained unchanged regardless of how we defined 20-yrs follow-up participants (results not shown).

While baseline prevalence estimates were somewhat altered when excluding those lost to follow-up in the present study, the 9 exposure-outcome associations analysed were mainly unchanged. Such a tendency has also been noted by others [16,23,32,33], and may indicate that internal causal associations are less vulnerable to selection bias than prevalence estimates. It should be noted, however, that the focus of the present paper was associations at baseline. Exposure-outcome associations based on one of the follow-up studies with both the follow-up population and those lost to follow-up included might have resulted in different estimates. Since those lost to follow-up per definition will never be included in a follow-up study, this will of course be a purely theoretical speculation.

Future prevalence reports from RHINE, I-ECRHS and ISAYA should take the results from the present study into account and interpret prevalence rates accordingly. For instance, knowing that the baseline prevalence of wheeze in RHINE was $8 \%$ lower among long-term participants than among the total baseline participants should have consequences for the interpretation of wheeze prevalence in a later follow-up study. If wheeze prevalence at a follow-up study is for instance $25 \%$, we should take into account that the "true" wheeze prevalence is likely to be approximately $8 \%$ higher, i.e. $27 \%$. Also, knowing that the baseline prevalence of rhinitis in ISAYA was $14 \%$ higher among long-term participants than among the total baseline participants would infer a similar interpretation of rhinitis prevalence in a later follow-up study: a rhinitis prevalence of for instance $20 \%$ in a follow-up study would indicate a "true" rhinitis prevalence to be $14 \%$ higher, i.e. $22.8 \%$.

Bias in baseline prevalence estimates may also have consequences for follow-up estimations on incidence, remission and in some instances also risks. The lower baseline prevalence of respiratory symptoms among long-term participants as compared to total baseline participants that we found in the present study may indicate a healthy survivor effect in the study. Such an effect is most commonly observed in association with occupation, in that persons who remain employed tend to be healthier than those who leave employment. However, it is also plausible that persons who continue to participate in a study is healthier than persons who quit their study participation, especially in a study with such a long follow-up period as the RHINE and the Italian ECRHS have. Incidence and remission estimates in the follow-up stages of these studies may both be under-estimated compared to true population estimates if the follow-up population is generally healthier than the 
total population. However, in the present study we did not find very large variations in baseline prevalence estimates, and the effects on incidence and remission estimates later on in the study are consequently likely to be small. Future incidence investigations based on the three studies covered here should nevertheless take into account the observed baseline differences between total baseline participants and long-term participants in the interpretation of results.

\section{Merits and limits of the study}

The main strengths of this study are 1) the large sample size, 2) the extensive follow-up time, and 3) the use of a methodology that is well suited to assess size and direction of selection bias in long-term follow-up. Certain limitations should also be acknowledged: firstly, the lack of information on predictors for baseline participation. We have examined long-term participation but know litthe of potential selection bias at baseline. Secondly, the three studies in this report have not been conducted at exactly the same points in time. This is especially relevant for ISAYA, which started 10 years after ECRHS and RHINE. However, since the results are essentially the same between studies with regard to follow-up participation patterns, we do not believe that the time aspect is vital in this context. Thirdly, we have focused on a limited amount of selected exposures and outcomes. To be sure that loss to follow-up does not bias other effect estimates, all possible exposures and outcomes should in principle have been examined in the same way. However, this is not feasible. Although many associations remain to be analysed, we believe that the selection of different exposures and outcomes in the present paper gives an indication of the validity of RHINE, I-ECRHS and ISAYA.

\section{Conclusions}

To conclude, increasing age and female sex were predictors for long-term participation. Prevalence estimates from the follow-up populations should be interpreted with some caution in future reports from RHINE, I-ECRHS and ISAYA since they tended to be slightly lower than for the total baseline population. Exposure-outcome associations, on the other hand, were mainly unchanged by loss to follow-up. Although response rates varied between studies, the present results indicate high validity in the data from RHINE, I-ECRHS and ISAYA.

\section{Additional file}

Additional file 1: Online supplement material.

\section{Competing interests}

The authors declare that they have no competing interests.

\section{Authors' contributions}

AJ, GV, BB, BF, KF, TG, MH, CJ, RJ, EL, FM, ER, FGR, EWS, VS, TS, TDS, CS, KT, MW and RdM carried out the studies included in the present paper (RHINE, I-ECRHS and ISAYA), participated in study design, coordination and data collection. AJ performed the statistical analyses and drafted the manuscript. GV, RMN and RdM participated with guidance regarding the statistical analyses and helped draft the manuscript. All authors provided input on previous versions of the manuscript, and all authors read and approved the final manuscript.

\section{Acknowledgements}

All co-authors were involved in the collection of data for the present study. In addition, local coordinators for the Italian study centers were P Pirina (Sassari), M Bugiano (Turin) and S Villani (Pavia).

\section{Author details}

'Centre for Clinical Research, Haukeland University Hospital, Bergen 5021, Norway. ${ }^{2}$ Sezione di Epidemiologia \& Statistica Medica, Università di Verona, Verona, Italy. ${ }^{3}$ Department of Allergy, Respiratory Medicine and Sleep, Landspitali University Hospital, Reykjavik, Iceland. ${ }^{4}$ Division of Occupational and Environmental Medicine, Department of Public Health and Clinical Medicine, Umeå University, Umeå, Sweden. ${ }^{5}$ Surgical and Perioperative Sciences, Umeå University, Umeå, Sweden. ${ }^{6}$ Department of Occupational and Environmental Medicine, Sahlgrenska University Hospital, Gothenburg, Sweden. ${ }^{7}$ Department of Medical Sciences: Respiratory Medicine and Allergology, Uppsala University, Uppsala, Sweden. ${ }^{8}$ Lung Clinic, University of Tartu, Tartu, Estonia. ${ }^{9}$ Department of Obstetrics and Gynecology, Haukeland University Hospital, Bergen, Norway. ${ }^{10}$ Institute of Medicine, Bergen University, Bergen, Norway. ${ }^{11}$ Department of Public Health, Section for Environment, Work and Health, Aarhus University, Aarhus, Denmark. ${ }^{12}$ Department of Occupational Medicine, Aarhus University Hospital, Aarhus, Denmark. ${ }^{13}$ Department of Occupational Medicine, Haukeland University Hospital, Bergen, Norway. ${ }^{14}$ Section of Occupational and Environmental Medicine, University of Gothenburg, Gothenburg, Sweden.

Received: 7 January 2014 Accepted: 3 April 2014

Published: 16 April 2014

\section{References}

1. Rothman K, Greenland S, Lash TL: Modern epidemiology. 3rd edition. Philadelphia, USA: Lippincott Williams \& Wilkins; 2008.

2. Susser M, Susser E: Choosing a future for epidemiology: I. Eras and paradigms. Am J Public Health 1996, 86(5):668-673.

3. Little RJ, D'Agostino R, Cohen ML, Dickersin K, Emerson SS, Farrar JT, Frangakis C, Hogan JW, Molenberghs G, Murphy SA, Neaton JD, Rotnitzky A, Scharfstein D, Shih WJ, Siegel JP, Stern H: The prevention and treatment of missing data in clinical trials. N Engl J Med 2012, 367(14):1355-1360.

4. Grimes DA, Schulz KF: Bias and causal associations in observational research. Lancet 2002, 359(9302):248-252.

5. Rochon PA, Gurwitz JH, Sykora K, Mamdani M, Streiner DL, Garfinkel S, Normand SL, Anderson GM: Reader's guide to critical appraisal of cohort studies: 1. Role and design. BMJ 2005, 330(7496):895-897.

6. Van Amelsvoort LG, Beurskens AJ, Kant I, Swaen GM: The effect of non-random loss to follow-up on group mean estimates in a longitudinal study. Eur J Epidemiol 2004, 19(1):15-23.

7. Kristman V, Manno M, Cote P: Loss to follow-up in cohort studies: how much is too much? Eur J Epidemiol 2004, 19(8):751-760.

8. Greene N, Greenland S, Olsen J, Nohr EA: Estimating bias from loss to follow-up in the Danish National Birth Cohort. Epidemiology 2011, 22(6):815-822.

9. Eriksson AK, Ekbom A, Hilding A, Ostenson CG: The influence of nonresponse in a population-based cohort study on type 2 diabetes evaluated by the Swedish Prescribed Drug Register. Eur J Epidemiol 2012, 27(3):153-162.

10. Burney PG, Luczynska C, Chinn S, Jarvis D: The European Community Respiratory Health Survey. Eur Respir J 1994, 7(5):954-960.

11. Toren K, Gislason T, Omenaas E, Jogi R, Forsberg B, Nystrom L, Olin AC, Svanes $C$, Janson C, RHINE Group: A prospective study of asthma incidence and its predictors: the RHINE study. Eur Respir J 2004, 24(6):942-946. 
12. de Marco R, Poli A, Ferrari M, Accordini S, Giammanco G, Bugiani M, Villani S, Ponzio M, Bono R, Carrozzi L, Cavallini R, Cazzoletti L, Dallari R, Ginesu F, Lauriola P, Mandrioli P, Perfetti L, Pignato S, Pirina P, Struzzo P, ISAYA study group: Italian Study on Asthma in Young Adults: The impact of climate and traffic-related NO2 on the prevalence of asthma and allergic rhinitis in Italy. Clin Exp Allergy 2002, 32(10):1405-1412.

13. Janson C, Anto J, Burney P, Chinn S, de Marco R, Heinrich J, Jarvis D, Kuenzli N, Leynaert B, Luczynska C, Neukirch F, Svanes C, Sunyer J, Wjst M, European Community Respiratory Health Survey II: The European Community Respiratory Health Survey: what are the main results so far? European Community Respiratory Health Survey II. Eur Respir J 2001, 18(3):598-611.

14. De Marco R, Verlato G, Zanolin E, Bugiani M, Drane JW: Nonresponse bias in EC Respiratory Health Survey in Italy. Eur Respir J 1994, 7(12):2139-2145.

15. Verlato G, Melotti R, Olivieri M, Corsico A, Bugiani M, Accordini S, Villani S, Migliore E, Marinoni A, Pirina P, Carrozzi L, Bortolami O, Rava M, de Marco R, ISAYA study group: Asthmatics and ex-smokers respond early, heavy smokers respond late to mailed surveys in Italy. Respir Med 2010, 104(2):172-179.

16. Nilsen RM, Vollset SE, Gjessing HK, Skjaerven R, Melve KK, Schreuder P, Alsaker ER, Haug K, Daltveit AK, Magnus P: Self-selection and bias in a large prospective pregnancy cohort in Norway. Paediatr Perinat Epidemiol 2009, 23(6):597-608.

17. Austin MA, Criqui MH, Barrett-Connor E, Holdbrook MJ: The effect of response bias on the odds ratio. Am J Epidemiol 1981, 114(1):137-143.

18. Pizzi C, De Stavola B, Merletti F, Bellocco R, Dos Santos SI, Pearce N, Richiardi L: Sample selection and validity of exposure-disease association estimates in cohort studies. J Epidemiol Community Health 2011, 65(5):407-411.

19. Nilsen RM, Suren P, Gunnes $N$, Alsaker ER, Bresnahan M, Hirtz D, Hornig M, Lie KK, Lipkin WI, Reichborn-Kjennerud T, Roth C, Schjolberg S, Davey Smith G, Susser E, Vollset SE, Oyen AS, Magnus P, Stoltenberg C: Analysis of Selfselection Bias in a Population-based Cohort Study of Autism Spectrum Disorders. Paediatr Perinat Epidemiol 2013, 27(6):553-63.

20. Davison AC, Hinkley DV: Bootstrap methods and their application. Cambridge; New York, NY, USA: Cambridge University Press; 1997.

21. Burney PG, Luczynska C, Chinn S, Jarvis D: Variations in the prevalence of respiratory symptoms, self-reported asthma attacks, and use of asthma medication in the European Community Respiratory Health Survey (ECRHS). Eur Respir J 1996, 9(4):687-695.

22. Ronmark EP, Ekerljung L, Lotvall J, Toren K, Ronmark E, Lundback B: Large scale questionnaire survey on respiratory health in Sweden: effects of late- and non-response. Respir Med 2009, 103(12):1807-1815.

23. Batty GD, Gale CR: Impact of resurvey non-response on the associations between baseline risk factors and cardiovascular disease mortality: prospective cohort study. J Epidemiol Community Health 2009, 63(11):952-955.

24. Jooste PL, Yach D, Steenkamp HJ, Botha JL, Rossouw JE: Drop-out and newcomer bias in a community cardiovascular follow-up study. Int J Epidemiol 1990, 19(2):284-289.

25. Kotaniemi JT, Hassi J, Kataja M, Jonsson E, Laitinen LA, Sovijarvi AR, Lundback B: Does non-responder bias have a significant effect on the results in a postal questionnaire study? Eur J Epidemio/ 2001, 17(9):809-817.

26. Bakke PS, Ronmark E, Eagan T, Pistelli F, Annesi-Maesano I, Maly M, Meren M, Vermeire Dagger P, Vestbo J, Viegi G, Zielinski J, Lundback B, European Respiratory Society Task Force: Recommendations for epidemiological studies on COPD. Eur Respir J 2011, 38(6):1261-1277.

27. Hazell ML, Morris JA, Linehan MF, Frank PI, Frank TL: Factors influencing the response to postal questionnaire surveys about respiratory symptoms. Prim Care Resp J 2009, 18(3):165-170.

28. Ronmark E, Lundqvist A, Lundback B, Nystrom L: Non-responders to a postal questionnaire on respiratory symptoms and diseases. Eur $J$ Epidemiol 1999, 15(3):293-299.

29. Bakke P, Gulsvik A, Lilleng P, Overa O, Hanoa R, Eide GE: Postal survey on airborne occupational exposure and respiratory disorders in Norway: causes and consequences of non-response. J Epidemiol Community Health 1990, 44(4):316-320.

30. Vestbo J, Rasmussen FV: Baseline characteristics are not sufficient indicators of non-response bias follow up studies. J Epidemiol Community Health 1992, 46(6):617-619.
31. Asch DA, Jedrziewski MK, Christakis NA: Response rates to mail surveys published in medical journals. J Clin Epidemio/ 1997, 50(10):1129-1136.

32. Osler M, Kriegbaum M, Christensen U, Holstein B, Nybo Andersen AM: Rapid report on methodology: does loss to follow-up in a cohort study bias associations between early life factors and lifestyle-related health outcomes? Ann Epidemiol 2008, 18(5):422-424.

33. Eagan TM, Eide GE, Gulsvik A, Bakke PS: Nonresponse in a community cohort study: predictors and consequences for exposure-disease associations. J Clin Epidemiol 2002, 55(8):775-781.

doi:10.1186/1471-2466-14-63

Cite this article as: Johannessen et al:: Longterm follow-up in European respiratory health studies - patterns and implications. BMC Pulmonary Medicine 2014 14:63.

\section{Submit your next manuscript to BioMed Central and take full advantage of:}

- Convenient online submission

- Thorough peer review

- No space constraints or color figure charges

- Immediate publication on acceptance

- Inclusion in PubMed, CAS, Scopus and Google Scholar

- Research which is freely available for redistribution 